\title{
KELAYAKAN USAHA BUDIDAYA ULAT SUTERA (BOMBIX MORI L.) BERDASARKAN ASPEK NON FINANSIAL KABUPATEN BOALEMO
}

\author{
(The Feasibility Of The Business Of Cultivating Silkworms (Bombix Mori. L)Based On \\ The Aspect Of Non Financial Boalemo District)
}

\author{
Murni Djabar, Nurnaningsih Utiarahman \\ Universitas Gorontalo \\ Jln. A.A.Wahab NO.247 Kel.Kayu Bulan Kec.Limboto Kabupaten Gorontalo \\ murnidjabarug@gmail.com
}

\begin{abstract}
The purpose of this study was to determine the feasibility of the business based on nonfinancial aspects of silkworm cultivation. The results of this study were with high demand and with a guarantee of the cocoon market, silkworm cultivation business conducted in the Tangga Barito village, the working area of of KPHP Unit V Boalemo worthy of doing. Cocoon selling prices of Rp. 40,000 is a standard price that is appropriate for quality b (medium) cocoons. To increase the added value of mulberry cultivation, it can endeavor to manufacture mulberry tea which is used as an antioxidant drink or to process silkworm waste into organic fertilizer. For technical and technology aspects starting from the business location, the location of caterpillar maintenance in general is close to the residence so as to facilitate maintenance and supervision. Silkworm cultivation is prepared starting from the building of silkworms to how to control pests and diseases that attack silkworms. The organization in question consists of informing matters relating to the cultivation of silkworms, directing, coordinating the development of mulberry and silkworm maintenance demonstration plots. From these results the silkworm business is feasible to run.
\end{abstract}

Keywords: Aspect of non financial, Boalemo, Business feasibility, silkworms

\begin{abstract}
Abstrak
Tujuan dari penelitian ini adalah untuk mengetahui kelayakan usaha berdasarkan aspek non finansial usaha budidaya ulat sutera.Hasil dari penelitian ini adalah Dengan permintaan yang tinggi dan dengan adanya jaminan pasar kokon, usaha budidaya ulat sutera yang dilakukan di Desa Tangga Barito wilayah kerja KPHP Unit V Boalemo layak untuk dilakukan.Harga jual kokon sebesar Rp 40.000 merupakan harga standar yang sesuai untuk kokon berkualitas B (sedang). Untuk meningkatkan nilai tambah budidaya murbei, dapat mengusahakan pembuatan teh murbei yang dijadikan minuman antioksidan atau mengolah limbah ulat sutera menjadi pupuk organik. Untuk Aspek Teknis dan Teknologi mulai dari lokasi usaha, Lokasi pemeliharaan ulat secara umum berdekatan dengan tempat tinggal sehingga memudahkan pemeliharaan dan pengawasan.Budidaya Ulat sutera dipersiapkan mulai dari bangunan ulat sutera hingga pada cara mengendalikan hama dan penyakit yang menyerang Ulat sutera. Pengorganisasian yang dimaksud berupa menginformasikan hal-hal yang berkaitan dengan pembudidayaan ulat sutera, mengarahkan, mengkoordinir pembanguan demplot pemeliharaan murbei dan ulat sutera. Dari hasil penelitian tersebut maka usaha ulat sutera layak untuk dijalankan.
\end{abstract}

Kata Kunci: Aspek Non Finansial, Boalemo, Kelayakan Usaha, Ulat sutera 


\section{PENDAHULUAN}

Usaha persuteraan alam telah lama dikenal sebagian masyarakat Indonesia. Kegiatan ini bersifat padat karya, tidak mutlak memerlukan ketrampilan khusus yang tinggi, menghasilkan produk dengan nilai ekonomi yang tinggi serta relatif cepat menghasilkan. Diharapkan kegiatan ini dapat dijadikan alternatif usaha dalam upaya peningkatan pendapatan masyarakat pedesaan.

Dari rangkaian kegiatan persuteraan alam tersebut, dipandang dari aspek usaha sebenarnya dapat dibagi menjadi 2 atau 3 unit usaha yang masing-masing dapat berdiri menjadi unit usaha mandiri, yaitu usaha kebun murbei sebagai pemasok pakan ulat sutera, kemudian usaha pemeliharaan ulat sutera untuk menghasilkan kokon sutera dan usaha pemintalan kokon menjadi benang sutera siap tenun.

Peluang Indonesia menjadi pemasok produk sutera alam pada posisi 5 besar dunia bukanlah hal yang tidak mungkin. Kondisi agroklimat sangat mendukung kegiatan budidaya murbei dan ulat sutera. Selain itu, jumlah tenaga kerja, sosial, dan budaya sangat mendukung. Pinjaman modal dari pemerintah daerah setempat pun dapat diperoleh. Namun kenyataannya, perkembangan produksi benang sutera Indonesia dari tahun ke tahun mengalami fluktuasi yang cukup besar . Penurunan tersebut terjadi karena petani sutera beralih pada usaha tani lain yang lebih menguntungkan (Dephut RI 2008).

Penelitian mengenai kelayakan usaha perlu dilakukan untuk mengetahui layak atau tidaknya suatu usaha sehingga korbanan biaya yang dikeluarkan tidak menjadi sia-sia. Hal ini juga dapat menjadi bahan pertimbangan bagi pemerintah dalam menstabilkan dan memajukan persuteraan alam Indonesia yang beberapa tahun terakhir mengalami fluktuasi. Dengan demikian, permintaan benang sutera baik di dalam maupun di luar negeri dapat terpenuhi. Penelitian kelayakan usaha dilakukan dengan menganalisis aspek non finansial.

\section{METODE PENELITIAN}

Penelitian ini dilaksanakan di Desa Tangga Barito Kecamatan Dulupi Wilayah KPHP Unit V Boalemo dan waktu pelaksanaannya pada bulan Maret September 2019. Alat dan bahan yang digunakan adalah alat tulis menulis, kamera dan daftar pertanyaan untuk responden. Data primer diperoleh melalui wawancara dengan responden dan observasi langsung ke areal budidaya ulat sutera. Data sekunder diperoleh melalui wawancara dengan pelaksana kegiatan di KPHP Unit V. Selain itu, perolehan data sekunder dilakukan dengan penelusuran dokumen dan sumber informasi cetak lainnya.

\section{Analisa Data}

Data yang diperoleh dari data primer dan sekunder dianalisis secara kualitatif. Analisis kualitatif dilakukan dengan mendeskripsikan aspek-aspek kelayakan usaha, meliputi aspek pasar dan pemasaran, teknis dan teknologi, manajemen, sumberdaya manusia, yuridis, serta aspek lingkungan. 


\section{HASIL DAN PEMBAHASAN}

\section{Aspek Pasar}

Permintaan kokon di Indonesia sangat tinggi terutama yang berada di pulau jawa dan Sulawesi Selatan yang bersedia menampung seluruh hasil kokon, yang perlu dilakukan adalah membangun kemitraan. Kemitraan memiliki kemampuan dan kontribusi bagi hasil produksi sutera. Dalam pengembangan kelembagaan/usaha, kemitraan merupakan salah satu strategi yang ditempuh untuk mendukung keberhasilan implementasi manajamen modern. Kemitraan tidak sekedar diterjemahkan sebagai sebuah kerjasama, akan tetapi kemitraan memiliki pola, memiliki nilai strategis dalam mewujudkan keberhasilan usaha sutera alam. Diantaranya kesepahaman strategi pengembangan ulat sutera dengan prinsip partisipasi, prinsip gotong royong, prinsip keterbukaan dan prinsip penegakkan hukum untuk keberlanjutan kemitraan. Dengan permintaan yang tinggi dan dengan adanya jaminan pasar kokon, usaha budidaya ulat sutera yang dilakukan di Desa Tangga Barito wilayah kerja KPHP Unit V Boalemo layak untuk dilakukan.

Produk yang dihasilkan dapat berupa kokon dan stek murbei. Jumlah produksi kokon saat ini bisa mencapai 120 kilogram per bulan. Kualitas kokon yang dihasilkan secara umum berada pada kualitas sedang sehingga harga jual kokon sebesar Rp 40.000 per kilogram. Secara visual, kokon berkualitas sedang atau kelas B merupakan kokon dengan berat berkisar1,5 gram hingga 1,9 gram, persentase cacat kokon mencapai 1,1 persen hingga 4 persen, dan persentase kulit kokon mencapai 20 persen hingga 24,9 persen.

Tabel 2. Kriteria dan kelas kualitas kokon

\begin{tabular}{lcccc}
\hline Kriteria & \multicolumn{4}{c}{ Kelas Kualitas } \\
\cline { 2 - 5 } & A & B & C & D \\
\hline berat (gram) & $\geq 2$ & $1,5-1,9$ & $1-1,4$ & $\leq 0,9$ \\
cacat(\%) & $\leq 1$ & $1,1-4$ & $4,1-8$ & $\geq 9$ \\
kulitkokon & 25 & $20-24,9$ & $15-19,9$ & $\geq 14,9$ \\
\hline
\end{tabular}

Sumber: Santoso (1997) dalam Atmosoedarjo (2000)

Terdapat tiga kelompok dalam memenangkan persaingan pasar, yaitu keunggulan operasional (operational excellence), kepemimpinan produk (product leadership), dan keakraban dengan pelanggan (customer intimacy) (Treacy \& Wiersema 1995) dalam Tjiptono (2008). Budidaya ulat sutera harus memiliki konsumen/pelanggan tetap dan produk yang dihasilkan bukan bersifat operasional sehingga dapat memilih perluasan pangsa pasar dengan cara mengembangkan dan menginovasi produk yang dihasilkan. Strategi ini tepat ditujukan pada pelanggan yang mengutamakan keunikan produk. Untuk meningkatkan profitabilitas, produk yang dijual bukan hanya berupa kokon namun dapat berupa benang dan kerajinan tangan yang dibuat dari kokon yang layak jual.

\section{Aspek Pemasaran}

Produk merupakan suatu nilai yang didapat oleh konsumen sebagai pelaku pengambil keputusan pembelian. Dalam hal ini, kokon merupakan produk yang diperjualbelikan. Harga jual kokon sebesar Rp 
40.000 merupakan harga standar yang sesuai untuk kokon berkualitas B (sedang). Keuntungan penetapan harga ini yaitu kepastian harga yang menguntungkan pada saat kualitas kokon yang dihasilkan berada pada kualitas C dan D. Sedangkan kerugiaan, yaitu tidak mendapat harga kokon yang sesuai pada saat kualitas harga kokon yang dihasilkan mencapai kelas (grade) A.

Untuk meningkatkan nilai tambah, stek murbei dijual ke konsumen yang membutuhkan. Selain kokon, kepompong ulat sutera dan buah murbei (mulberry) dicari oleh konsumen lain. Untuk meningkatkan nilai tambah budidaya murbei, dapat mengusahakan pembuatan teh murbei yang dijadikan minuman antioksidan atau mengolah limbah ulat sutera menjadi pupuk organik.

\section{Aspek Teknis dan Teknologi}

a. Lokasi Usaha

Penempatan lokasi usaha berpengaruh terhadap biaya operasional dan biaya investasi sehingga perlu dilakukan sebaik mungkin dengan mempertimbangkan berbagai faktor (Suliyanto, 2010). Lokasi pemeliharaan ulat secara umum berdekatan dengan tempat tinggal sehingga memudahkan pemeliharaan dan pengawasan. Selain memudahkan pemeliharaan ulat dan pengawasan, pemilihan lokasi pemeliharaan ulat sutera berdasarkan pada letak kebun murbei, ketersediaan tenaga kerja, dan ketersediaan sumber air dan energi, serta fasilitas transportasi.

Letak kebun murbei dengan rumah ulat secara umum berdekatan, yaitu di sekitar rumah ulat hingga berjarak sekitar 300 meter. Kebun murbei dibuat dalam bentuk petakpetak atau gawang. Satu gawang memiliki luas sekitar 0.2 hektar hingga 0,3 hektar tergantung luasan lahan yang tersedia. Gawang yang satu dan lainnya sekitar 30 meter hingga 250 meter. Jarak ini tergantung dengan luasan lahan yang tersedia sehingga tidak dapat dikumpulkan menjadi satu.
Ahdiat (2007) menyatakan jarak kebun murbei yang berjauhan dengan rumah ulat mengakibatkan daun murbei sedikit layu sehingga kurang baik untuk perkembangan ulat sutera.

\section{b. Skala Produksi}

Jumlah produk yang diproduksi oleh perusahaan dalam periode tertentu harus direncanakan dengan matang agar keuntungan dapat dioptimalkan (Suliyanto, 2010). Jumlah ulat sutera yang dipelihara per tahun pada pertama skala usaha, yaitu 4 boks pada skala usaha I ( 2 ha), 10 boks pada skala usaha II (5 ha) dan 20 boks pada skala usaha III (10 ha).

\section{c. Budidaya Murbei}

Persiapan lahan dilakukan dengan membersihkan lahan, pengolahan tanah, dan pemupukan. Pembersihan lahan dilakukan secara manual, yaitu dengan melakukan pembabatan semak, ilalang, dan penebangan pohon yang dapat mengganggu perkembangan murbei. Semak, ilalang, dan ranting pohon dikumpulkan dan dibakar sedangkan kayu pohon dimanfaatkan sebagai kayu bakar maupun keperluan lainnya. Kemudian dilakukan pengolahan tanah dengan cara pencangkulan.

Ahdiat (2007) menyatakan jarak tanam murbei pada penanaman monokultur yaitu 100 $\mathrm{cm}$ x $50 \mathrm{~cm}$ dan jarak tanam murbei untuk penanaman secara tumpang sari yaitu $150 \mathrm{~cm}$ x $50 \mathrm{~cm}$,menanam murbei dalam larikan yang membujur dari utara ke selatan. Ini dimaksudkan agar penyinaran matahari lebih merata ke seluruh tanaman murbei. Larikan dibuat lebih tinggi dari sekitarnya agar tanaman mendapat asupan oksigen yang eukup. Jarak antara barisan satu dengan barisan lainnya, yaitu 120 sentimeter. Di dalam satu barisan, terdapat rorak atau lubang tanam yang dalamnya \pm 50 sentimeter. Jarak antara rorak yang satu dengan rorak lainnya sekitar 40 sentimeter. Dalam satu petak atau gawang, tanaman murbei dibagi per blok 
tanaman untuk mempermudah pemanenan. Pada saat pemanenan, daun murbei ditumpuk di antara blok satu dengan lainnya. Jarak antara satu tumpukan dengan tumpukan lainnya, yaitu sekitar 4 hingga 5 meter. Hasil panenan daun murbei dimasukkan ke dalam karung untuk dibawa ke rumah ulat sutera. Tanaman hortikultura yang ditumpangsarikan dengan tanaman murbei ditanam di antara larikan sehingga tidak terlalu mengganggu tanaman murbei.

Setelah dua minggu dilakukan pemupukan berupa pupuk kandang dan pupuk kimia yang disertai dengan pengadukan dengan lapisan top soil, ditimbun dengan lapisan sub soil dan diberi tanda ajir. Pemberian tanda ajir hanya dilakukan pada rorak di tepi lahan penanaman. Sedangkan penanaman pada rorak di tengah lahan mengikuti jalur ajir yang berada di tepi lahan. Pupuk dasar yang digunakan pada skala usaha I, yaitu 250 kilogram pupuk kandang, 50 kilogram urea, 50 kilogram NPK, dan 100 kilogram pupuk ZA.

Selanjutnya setelah proses pemupukan selesai dilakukan penanaman stek murbei dengan panjang \pm 25 sentimeter dengan diameter \pm 1 sentimeter hingga 1,5 sentimeter. Pemeliharaan yang dilakukan setiap tahunnya berupa penyiangan, penyulaman, pemangkasan, dan pemupukan. Pada tahun pertama dilakukan pendangiran untuk menjaga asupan oksigen di dalam tanah. Penyiangan dilakukan untuk membuang gulma tanaman sehingga tidak terjadi persaingan unsur hara di dalam tanah. Penyulaman dilakukan untuk mengganti tanaman yang mati atau yang terserang hama dan penyakit agar tidak menular ke tanaman yang sehat. Pemangkasan berguna untuk membentuk tajuk maupun menghilangkan bagian tanaman yang terkena hama maupun penyakit. Pemupukan tiap tahunnya dilakukan untuk memberikan asupan hara pada tanaman murbei maupun tanaman hortikultura.
Hama dan penyakit yang menyerang tanaman murbei biasanya kutu daun dan penggerek batang sedangkan untuk penyakit yaitu tepung, karat, bintik daun, dan bereak daun. Gejala murbei yang terserang hama penggerek batang yakni murbei melemah kemudian mati. Tanaman murbei harus dipotong dan dibakar. untuk menanggulangi penyakit pada murbei di lakukan penyemprotan fungisida

\section{Budidaya ulat Sutera}

Tempat penyimpanan daun murbei harus dipisah dari ruang pemeliharaan/penyimpanan peralatan pengokonan. Selain itu, daun murbei disusun berdiri dan tidak terlalu rapat serta ditutup dengan kain basah. Hal ini tidak dilakukan daun murbei menjadi sedikit layu dan kurang baik jika dikonsumsi oleh ulat sutera (Ahdiat , 2007),

Ventilasi atau lubang udara dibuat di dinding rumah ulat maupun di bagian atas dinding depan atau belakang rumah ulat. Ventilasi udara ditutupi oleh karung atau plastik mulsa, penutupan ventilasi berguna agar ulat tidak terkena udara langsung pada saat malam hari yang dingin.

Gudang memiliki fungsi untuk meletakkan peralatan pemeliharaan budidaya murbei dan peralatan pemeliharaan ulat sutera, di antaranya seriframe, hand sprayer, cangkul, sabit, golok, gaet, pisau rajang, tempat rajang, alat pikul, nanpan, gintiran, stik bambu, sapu lantai, dan lain sebagainya. Gunang berada di dalam rumah ulat bertujuan untuk mempermudah pengambilan peralatan jika dibutuhkan.

Rak ulat digunakan untuk tempat ulat pada saat pemeliharaan. Jumlah rak yang ada di dalam rumah ulat berkisar antara 2 hingga 3 rak. Satu rak terdiri dari 2 hingga 3 lantai. Jumlah rak tergantung pada jumlah ulat yang dipelihara. Rak yang tidak berisi ulat dijadikan tempat untuk meletakkan daun murbei. Daun murbei diletakkan berdekatan dengan ulat agar 
mudah dalam pemberian pakan sehingga dapat mengefisienkan waktu. Selain itu, rak juga digunakan untuk meletakkan peralatan budidaya murbei dan ulat sutera sehingga tidak memerlukan adanya gudang. Ahdiat (2007) menyatakan bahwa pemberian pakan ulat dilakukan empat kali dalam sehari agar pertumbuhan ulat menjadi lebih optimal yakni pada pagi hari, siang, sore dan malam hari. Memberi makan ulat sebanyak 3 kali dalam sehari, yaitu pada pukul 06.00, 12.00, dan pada pukul17.30. Pemberian kapur dilakukan setiap hari agar ulat terhindar dari berbagai penyakit yang berasal dari kotoran dan tangkai murbei. Desinfeksi ulat sutera menurut Ahdiat (2007) sebaiknya menggunakan eampuran kapur dan kaporit dengan perbandingan 9: 1 . Jumlah desinfektan untuk ulat besar yaitu sekitar 50 gr hingga 60 gr per meter persegi. Pemindahan sebagian ulat dilakukan seeara langsung maupun menggunakan nanpan untuk menjaga ruanggerak ulat sutera yang semakin hari bertambah besar.

Penyakit yang sering menyerang ulat sutera, yaitu grasserie (NPV), Infectious Flacherie (FV), Aspergillus, Muscardine, pebrin, bakteri, dan keracunan obat-obat pertanian. Gejala NPV pada ulat, yaitu kulit ulat membengkak, ulat membentuk kokon yang lembek dan kemudian mati, dan ulat mati menjadi lembek dan hitam. Gejala ulat yang terkena FV, yaitu nafsu makan berkurang, waktu ganti kulit tidak seragam, dan ulat muntah dan diare. Gejala penyakit Aspergillus, yaitu nafsu makan berkurang, mengeluarkan pencernaan sebelum mati, bangkai larva berwarna kuning atau coklat, dan muncul mycelia pada permukaan ulat yang mati. Gejala penyakit Muscardine, yaitu larva mengeras dan tidak membusuk, kotoran lunak, dan terdapat bintik-bintik besar di permukaan kulit ulat yang masih hidup. Gejala pebrin, yaitu nafsu makan berkurang, warna larva gelap, bintik-bintik eoklat kehitaman, larva dewasa berputar-putar tanpa membuat kokon, dan tubuh larva mengkerut, pertumbuhannya terhambat dan kemudian mati. Gejala ulat yang terkena bakteri, yaitu ulat menjadi lemah, metabolism turun, tubuh tidak elastie dan lunak, diare, dan ulat yang mati membusuk berwarna hitam dan mengeluarkan cairan berbau busuk. Sedangkan ulat yang terkena obat-obatan pertanian menunjukkan gejala berupa mengeluarkan cairan getah lambung, kaku, dan sering menggerakkan kepala.

Penanggulangan terhadap penyakit yang menyerang ulat sutera menurut Ahdiat (2007) dan Atmosoedarjo et al. (2000), yaitu desinfeksi ruangan dan peralatan pemeliharaan ulat menggunakan larutan kaporit atau formalin sebelum pemeliharaan, larva yang sakit harus dipisahkan dengan ulat yang sehat, memisahkan larva yang terlambat ganti kulit, tidak menggunakan daun yang menguning, layu, dan basah sebagai pakan ulat, tempat pembuangan kotoran ulat harus berjauhan dengan rumah ulat, pemeliharaan ulat tidak terlalu padat, dan tidak menanam murbei berdekatan dengan tembakau. Kebersihan rak pemeliharaan ulat dari kotoran ulat dan sisa makanan ulat berupa ranting murbei kurang terjaga sehingga menjadi sumber penyakit dan menghambat pertumbuhan ulat. Ahdiat (2007) menyatakan pembersihan kotoran ulat instar IV dilakukan pada hari ke dua pemeliharaan dan setelah tidur. Sedangkan pembersihan kotoran ulat instar V dilakukan setiap dua hari sekali atau setiap hari tergantung kondisi kotoran dan sisa makanannya.

Penjemuran kokon di bawah terik matahari dilakukan sebelum pemanenan. Hal ini bertujuan agar kokon menjadi kering dan mempermudah pemanenan. Kokon dikeluarkan dari seriframe menggunakan stik bambu. Serabut kokon atau floss dihilangkan dengan cara manual menggunakan tangan. menggunakan gintiran yang dibuat sendiri sehingga pekerjaan menjadi lebih mudah dan lebih cepat. Setelah 
itu, kokon diletakkan di atas rak pemeliharaan ulat yang telah dibersihkan dengan diberi alas karung. Kokon siap untuk dijual. Pengemasan kokon dilakukan untuk mempermudah pengangkutan ke tempat penjualan. Kokon dimasukkan ke dalam karung berukuran besar yang diikat ujungnya agar kokon tidak berhamburan.

\section{Peralatan dan Teknologi}

Secara umum, peralatan dan teknologi yang digunakan masih sederhana. Untuk membawa hasil panen murbei ke rumah ulat dilakukan dengan pemikulan dengan atau tanpa alat pikul. Pemanenan kokon pada setiap skala usaha dilakukan secara manual dengan menggunakan stik bambu untuk mengeluarkan kokon dari seriframe tanpa menggunakan peralatan khusus. Menghilangkan serabut luar dari kokon (floss atau kebatori) hanya dengan tangan tanpa menggunakan mesin pembersih serabut kokon (floss removal).

\section{Aspek Manajemen}

\section{a. Fungsi Perencanaan}

Perencanaan mengenai penanaman murbei, pemeliharaan murbei, pemanenan dan pengangkutan murbei, pemeliharaan ulat sutera, dan pemanenan ulat sutera dilakukan dengan bekal penyuluhan dan pelatihan yang diperoleh sebelum maupun selama menjalankan usaha budidaya ulat sutera. KPHP Unit V melakukan perencanaan mengenai pengembangan persuteraan alam bekerjasama dengan Pusat Penelitian Pengembangan Hutan dan Pusat Penelitian Pengembangan Sosial Ekonomi Kebijakan dan Perubahan Iklim, Badan Penelitian Pengembangan dan Inovasi Kementerian Lingkungan Hidup dan Kehutanan dalam meningkatkan produktivitas dan mutu kokon. b. Fungsi Pengorganisasian

Pengorganisasian bersifat formal dilakukan kepala KPHP yang bertindak sebagai pemimpin. Fungsi pengorganisasian merupakan kegiatan yang mengatur tugas, wewenang, dan tanggung jawab. Pengorganisasian yang dimaksud berupa menginformasikan halhal yang berkaitan dengan pembudidayaan ulat sutera, mengarahkan, mengkoordinir pembanguan demplot pemeliharaan murbei dan ulat sutera.

\section{c. Fungsi Pelaksanaan}

Koordinator lapangan menggerakkan bawahannya, bersikap dan berperilaku sesuai dengan yang diperlukan. mMngkoordinasikan setiap informasi yang diterima dari kepala KPHP Unit V dan menyampaikan ke pelaksana di tingkat laoangan. Keputusan mengenai perencanaan kegiatan pemeliharaan murbei dan ulat sutera sepenuhnya berada di tangan pelaksana lapanagan. Koordinator hanya memberikan saran dan arahan agar kegiatan persuteraan berjalan dengan lancar.

\section{d. Fungsi Pengendalian}

Fungsi pengendalian dipegang oleh Ketua KPHP. Melakukan peninjauan langsung ke lokasi pembudidayaan ulat sutera untuk mengetahui pelaksanaan pembudidayaan yang sedang dilakukan yang berkoordinasi dengan koordinator lapangan. Pelaksanaan fungsi-fungsi manajerial tersebut, dapat dikatakan bahwa usaha pembudidayaan ulat sutera ini layak dijalankan.

\section{SIMPULAN}

Budidaya ulat sutera yang akan di lakukan Di Desa Tangga Barito oleh KPHP Unit V Boalemo, layak dilaksanakan 
berdasarkan analisis aspek-aspek non finansial.

\section{DAFTAR PUSTAKA}

Ahdiat N. 2007. Bombyx mori: Ulat Penghasil Sutera. Ed-1. Bandung: Sinergi Pustaka Indonesia

Atmosoedarjo S, Kartasubrata J, Kaomini M, Saleh W, Moerdoko W. 2000.

Sutera Alam Indonesia. Jakarta: Yayasan Sarana Wahana Jaya.

[Dephut RI] Direktorat Jenderal Rehabilitasi Lahan dan Perhutanan Sosial Departemen Kehutanan Republik Indonesia. 2008. Statistik Kehutanan Indonesia Tahun 2008. Jakarta: Departemen Kehutanan Republik Indonesia.

Halim A. 2009. Analisis Kelayakan Investasi Bisnis. Yogyakarta: Graha Ilmu. Herlianto $\mathrm{H}$, Pujiastuti $\mathrm{T}$. 2009. Studi Kelayakan Bisnis. Yogyakarta: Graha Ilmu

Kadariah, Karlina L, Gray C. 1999. Pengantar Evaluasi Proyek. Ed Revisi. Jakarta: Fakultas Ekonomi, Universitas Indonesia.

Suliyanto. 2010. Studi Kelayakan Bisnis Murbei dan ulat sutera. Yogyakarta:.

Tajima Y. 1978. The silkworm, an Important Laboratory Tool. Tokyo: Kodansha.

Tjiptono F. 2008. Strategi Pemasaran. Yogyakarta:

Treacy M and Wiersema F. 1995. The discipline of market leaders. MA: Addison- Wesley Publishing Company.

Umar R. 2003. Riset Pemasaran dan Perilaku Konsumen. Jakarta: Gramedia Pustaka 